\title{
Emergency Nurses' Perception of Department Design as an Obstacle to Providing End-of-Life Care
}

\author{
Renea L. Beckstrand \\ Brigham Young University - Provo \\ Ryan J. Rasmussen \\ Karlen E. (Beth) Luthy \\ Brigham Young University - Provo, beth_luthy@byu.edu \\ Sondra Heaston \\ Brigham Young University - Provo
}

Follow this and additional works at: https://scholarsarchive.byu.edu/facpub

Part of the Critical Care Nursing Commons, and the Other Nursing Commons

\section{Original Publication Citation \\ Beckstrand, R. L., Rasmussen, R.**, Luthy, K. E., \& Heaston, S. (2012). Emergency nurses' perception of department design as an obstacle to providing end-of-life care. Journal of Emergency Nursing, 38(5), e27-e32.}

\section{BYU ScholarsArchive Citation}

Beckstrand, Renea L.; Rasmussen, Ryan J.; Luthy, Karlen E. (Beth); and Heaston, Sondra, "Emergency Nurses' Perception of Department Design as an Obstacle to Providing End-of-Life Care" (2012). Faculty Publications. 5235.

https://scholarsarchive.byu.edu/facpub/5235

This Peer-Reviewed Article is brought to you for free and open access by BYU ScholarsArchive. It has been accepted for inclusion in Faculty Publications by an authorized administrator of BYU ScholarsArchive. For more information, please contact ellen_amatangelo@byu.edu. 


\section{EMERGENCY Nurses' Perception of Department Design as an Obstacle to Providing END-OF-Life CARE}

Authors: Renea L. Beckstrand, PhD, RN, CCRN, CNE, Ryan J. Rasmussen, MS, FNP-c, Karlen E. Luthy, DNP, FNP-C, and Sondra Heaston, FNP-c, APRN, Provo and Pleasant Grove, UT

Introduction: Of the 119.2 million visits to the emergency department in 2006, it was estimated that about 249,000 visits resulted in the patient dying or being pronounced dead on arrival. In 2 national studies of emergency nurses' perceptions of end-of-life (EOL) care, ED design was identified as a large and frequent obstacle to providing EOL care. The purpose of this study was to determine the impact of ED design on EOL care as perceived by emergency nurses and to determine how much input emergency nurses have on the design of their emergency department.

Methods: A 25-item questionnaire regarding ED design as it affects EOL care was sent to a national, geographically dispersed, random sample of 500 members of ENA. Inclusion criteria were nurses who could read English, worked in an emergency department, and had cared for at least one patient at the EOL. Descriptive statistics were calculated for the Likert-type and demographic items. Open-ended questions were analyzed using content analysis.
Results: Two mailings yielded 198 usable responses. Nurses did not report that ED design was as large an obstacle to EOL care as previous studies had suggested. Nurses reported that the ED design helped EOL care at a greater rate than it obstructed EOL care. Nurses also believed they had little input into unit design or layout changes. The most common request for design change was private places for family members to grieve. Thirteen nurses also responded with an optional drawing of suggested ED designs.

Discussion: Overall, nurses reported some dissatisfaction with ED design and believed they had little to no input in unit design improvement. Improvements to EOL care might be achieved if ED design suggestions from emergency nurses were considered by committees that oversee remodeling and construction of emergency departments. Further research is needed to determine the impact of ED design on EOL care in the emergency department.

Key words: Emergency department; Design; Nurses' perception; End of life
$\mathrm{T}$ he emergency department is often a forgotten part of the health care system until individuals or their family members become ED patients. The

\footnotetext{
Renea L. Beckstrand is Associate Professor, College of Nursing, Brigham Young University, Provo, UT.

Ryan J. Rasmussen is a Family Nurse Practitioner, Lone Peak Pediatrics, Pleasant Grove, UT.

Karlen E. Luthy is Assistant Professor, College of Nursing, Brigham Young University, Provo, UT.

Sondra Heaston is Associate Teaching Professor, College of Nursing, Brigham Young University, Provo, UT.

For correspondence, write: Renea L. Beckstrand, PhD, RN, CCRN, CNE, PO Box 25432, 422 SWKT, Provo, UT 84602; E-mail: renea@byu.edu.

J Emerg Nurs 2012;38:e27-e32.

Available online 15 May 2012.

0099-1767/\$36.00
}

Copyright (C) 2012 Emergency Nurses Association. Published by Elsevier Inc. All rights reserved.

doi: $10.1016 /$ j.jen.2011.12.019
National Hospital Ambulatory Medical Care survey reported 119.2 million ED visits in 2006. ${ }^{1}$ These 119.2 million visits average to be about 40.5 visits per 100 people nationally. ${ }^{1}$ These numbers represent large increases compared with 1996 statistics, which reported 90.3 million ED visits, or a rate of 34.2 visits per 100 people. $^{1}$

Increasing visit rates indicate that emergency departments are becoming the front line of health care for more Americans every year. With increasing visit rates come more patients who are at the end of life (EOL) or are dying. Of the 119.2 million visits to the emergency department, it was estimated that about 249,000 visits resulted in the patient dying or being pronounced dead on arrival. ${ }^{1}$

Because of the high numbers of deaths occurring in emergency departments, 2 national studies looked at the largest and most frequent obstacles perceived by emergency nurses relating to EOL care. Using a random national sample of 300 emergency nurses, one study reported that "poor design of emergency departments not allowing for privacy of the dying patient or the grieving family mem- 
bers" ranked as the third-highest obstacle to providing EOL care in emergency departments. ${ }^{2}$ A follow-up study that included frequency of occurrence data had the same obstacle of "poor unit design as it affects EOL care" ranked second overall out of 28 obstacles. ${ }^{3}$ This item had a magnitude score (obstacle size multiplied by obstacle frequency) of 11.01 out of a possible 11.45 . We found no other articles in the literature that addressed the effect of ED design and layout on EOL care in emergency departments.

Experienced emergency nurses know that one of the major concerns with department design is patient privacy. Patient privacy has always been an issue in health care, but privacy became a part of federal law with the passing of the Health Insurance Portability and Accountability Act of 1996 (HIPAA). The major goal of HIPAA was to ensure that patients' health information was properly protected while still allowing for the proper flow of health information needed to provide high-quality health care. ${ }^{4}$ Concern for privacy in often overcrowded emergency departments includes basic layout problems such as the use of curtains between patients with no provision for private communication or private care and limited space provided for family members to be present. Understandably, the layout of emergency departments is something that cannot be easily changed, but improvements that affect the care of dying patients should be a consideration when planning for new or remodeled departments.

Because of the increasing numbers of patients who are at the EOL or die in the emergency department, a determination of the impact of ED design on EOL care is needed. The following research questions were asked:

1. What is the perception of emergency nurses regarding the frequency with which ED design obstructs their ability to care for dying patients?

2. What is the perception of emergency nurses regarding the frequency with which ED design helps or supports their ability to care for dying patients?

3. What is the perception of emergency nurses regarding the degree of difficulty in fixing the largest ED design problems as they affect EOL care?

4. What is the perception of emergency nurses regarding the amount of input or influence they have in the current layout or design of their emergency department?

5. What is the perception of emergency nurses regarding the most helpful potential design changes to improve EOL care in an emergency department?

6. What design and layout suggestions do emergency nurses have for emergency departments?

\section{Methods}

SUBJECTS

Institutional Review Board approval was obtained for this study. A geographically dispersed random sample of 500 emergency nurses was obtained from the National ENA. As of January 2010, ENA membership totaled 35,757 members, and thus this 500-member sample represented approximately $1.4 \%$ of the total ENA membership. ${ }^{5}$

ENA members who were considered eligible for the study had worked for some time in an emergency department, lived in the United States, were able to read English, and had cared for at least one patient at the EOL in an emergency setting. Completion of the questionnaire signified consent to participate.

\section{INSTRUMENT}

A questionnaire titled, "Emergency Nurses' Perceptions of Department Design as an Obstacle to End-of-Life Care" was developed using information gathered from a literature review, previously completed research, and expert opinion. The questionnaire was pretested by 24 experienced emergency nurses at 2 separate hospitals in the western United States. Minor changes in wording were made based on the recommendations of the nurses who pretested the tool. The tool took about 10 minutes to complete.

The final questionnaire contained a total of 25 items. Items included 4 Likert-type questions with an option to add additional comments for each item, one question allowing nurses to rank potential design changes they would like in their emergency department, and 4 openended questions about how frequently ED design has obstructed or helped in the care of EOL patients. Subjects were also asked to report how difficult or easy it would be to make changes to their emergency departments and to report about the influence emergency nurses had on current layout or design features in their departments. Eleven demographic questions were included, along with an optional area to sketch a layout or design suggestion.

\section{PROCEDURE}

A random sample of registered nurses ( $\mathrm{RNs}$ ) who were members of ENA was obtained. Included in the first mailing to the nurses was a letter of explanation, a copy of the questionnaire, a $\$ 1$ bill as compensation for completing the questionnaire, and a self-addressed stamped return envelope. A second mailing completed about 6 to 8 weeks after the first mailing was sent to those who did not respond to the first mailing and included a cover letter, a copy of the questionnaire, and a self-addressed stamped return envelope. Survey responses were entered into SPSS software. Data were ana- 
TABLE 1

Demographics of nurses ${ }^{a}$

Characteristic

n

$\%$

SD

Range

Sex

Female

159

80.3

Male

38

19.2

Did not report

0.5

Age (y)

47.3

10.3

23-68

19.8

12.3

$1-47$

15.0

10.7

$0-45$

Years in emergency department

31.1

14.4

$0-80$

No. of beds in emergency department

30.0

17.5

4-88

No. of dying patients cared for

$>30$

58.0

21-30

6.7

$11-20$

13.0

5-10

11.4

$<5$

9.8

Highest degree earned

Diploma

Associate

Bachelor

Master-nursing

Doctoral

Ever certified as CEN

Yes

No

Currently CEN

Yes

No

Years as CEN

Practice area

Direct care/bedside nurse $\quad 39.5$

Staff/charge nurse $\quad 33.7$

Clinical nurse specialist $\quad 1.6$

Other (manager, educator, etc) 26.8

Hospital type

$\begin{array}{ll}\text { Community, non-profit } & 61.5\end{array}$

Community, profit $\quad 18.8$

University medical center $\quad 11.5$

State hospital $\quad 1.0$

County hospital $\quad 2.6$

Military hospital $\quad 1.6$

$\begin{array}{ll}\text { Other } & 3.0\end{array}$

${ }^{a} \mathrm{~A}$ total of 500 questionnaires were sent, of which 215 were returned, 198 were usable, and 17 were not eligible, for a $40.9 \%$ response rate. 
lyzed for frequencies and measures of central tendency and dispersion. Open-ended text comments were reviewed by the principle investigator and an experienced emergency nurse for seminal examples of each item.

\section{Results}

Out of 500 potential respondents, a total of $215 \mathrm{RNs}$ returned questionnaires. Sixteen questionnaires were returned as undeliverable, and one questionnaire was returned unanswered, with the subject stating she was ineligible. Therefore usable responses were received from 198 nurses for a response rate of $40.9 \%$ after 2 mailings.

Of the subjects who responded to gender, $80.7 \%(n=159)$ were women and $19.3 \%(n=38)$ were men. The average age of participating nurses was 47.3 years $(S D=10.27)$, with a range of 23 to 68 years. Other demographic data including education, certification, and years as an $\mathrm{RN}$ are reported in Table 1.

The first item on the questionnaire was, "How frequently has the design of your emergency department obstructed your ability to care for dying patients and/or their families?" The range of choices were from 0 to 6 with $0=$ never, $1=$ less than once a month, $2=$ once $\mathrm{a}$ month, $3=2-3$ times a month, $4=$ once a week, $5=2-3$ times a week, and $6=$ daily (or every time I work). The mean score for this item was $1.45(S D=1.55 ; n=194)$, meaning that this sample of ED nurses reported the design of their emergency department obstructed their ability to care for dying patients or their families at a frequency of between less than once a month to once a month.

Because of the lack of previous information regarding how ED design affects EOL care, nurses were allowed to make comments to scored items for clarification $(n=$ 40). After analyzing comments by nurses on this item, 2 themes emerged. First, the issue of lack of privacy for dying patients and grieving families was exemplified by one emergency nurse who wrote, "Some of our rooms are snug and make it difficult for everyone to physically fit. A few of the rooms are separated by curtains, allowing other patients and families to hear the family or a dying patient grieve." A second theme pertained to the physical layout of the department, with the lack of space for family members at the bedside or in the waiting room. One nurse's example of a poorly planned department layout was illustrated by her statement, "One bad thing is, when going from the trauma or code room to CT scan or elevators, [we always have to] pass by the family room."

The second item on the questionnaire was, "How frequently has the design of your ED helped or supported your ability to care for the dying patients and/or their families?" This item had the same frequency scale ranging from 0 to 6 with $0=$ never and $6=$ daily or every time I work. The mean for this item was $2.25(\mathrm{SD}=2.09 ; n=$ 189), meaning that the design of the emergency department helped emergency nurses care for the dying patient or family between at least once a month and 2 to 3 times a month.

Similar to the first item, open-ended comments for this item also discussed both space and privacy. Nurses' written comments included, "We have a 'family' room which has easy access from the lobby and is located in a 'corner' position in our ED." Another nurse wrote, "We have private rooms with doors that are easily accessible and can be used for the dying patient's family."

The third item asked, "How difficult or easy would it be to fix the largest design or layout problems in your emergency department?" This item was a scaled question with 7 possible responses: $1=$ impossible, $2=$ very difficult, 3 = difficult, $4=$ somewhat difficult, 5 = somewhat easy, $6=$ easy, and $7=$ very easy. The mean score for this item was $2.90(\mathrm{SD}=1.39 ; n=187)$; nurses reported that on average it would be difficult for their hospital to fix the largest design or layout problem in the emergency department. In fact, when looking at all the nurses' responses for this item, $160(85.6 \%)$ reported it would be between difficult to impossible to fix design problems in their emergency department.

Fifty nurses made comments associated with this item. The most common comment referred to the lack of space, including both the lack of space in their current emergency department and the lack of space for potential remodeling. The second theme noted that many departments where these nurses currently work have recently been remodeled, are in the process of being remodeled, or recently were built new.

The fourth item was, "How much input or influence do you have (or have you had) in the design or layout of your ED?" This item was a scaled question with 5 possible responses: $1=$ none, $2=$ very little input, $3=$ some input, $4=$ much input, and $5=$ very much input. The mean score was $2.14(\mathrm{SD}=1.15 ; n=197)$, indicating that nurses believed they had between very little input and some input on the design or layout of their emergency department. Nurses commenting on this item $(n=24)$ shared they either had no input or their input wasn't listened to during design changes or remodels in their emergency department. One nurse expressing frustration wrote, "We just built a brand new emergency department and all of our suggestions were ignored. Things like [suggestions for] placement of sharps containers and automatic door openers have not been addressed." 


\section{TABLE 2}

\section{Potential design changes ranked from lowest to highest mean}

\section{Potential design changes}

1. Private places for family members to grieve

2. More private rooms for patients

3. More room for family presence such as during resuscitation

4. More rooms for observation

5. A chapel near the emergency department

Other added responses:

a. Availability of larger rooms for equipment and ease of access.

b. The availability of a chaplain or social worker.

c. More nursing staff to help ease workload.

$\begin{array}{lll}\text { Mean } & \text { SD } & \boldsymbol{n} \\ 2.45 & 1.22 & 175 \\ 2.66 & 1.53 & 161 \\ 2.77 & 1.39 & 170 \\ 3.08 & 1.41 & 159 \\ 3.82 & 1.43 & 163\end{array}$


of the aspects that were previously perceived as negatives. One study that looked at emergency nurses' satisfaction both before and after a remodeling of an emergency department indicated nurses had increased confidence and decreased stress levels after the remodel compared with before the remodel. ${ }^{6}$

Not surprisingly, many nurses believed they had little input or influence in the design or layout of their department. According to the position statement from ENA on EOL care, emergency nurses should work with their institutions to develop programs and be involved in research to provide better care to patients during EOL care. ${ }^{7}$

Many emergency departments have been designed using concepts developed in previous decades and for much lower patient volumes than those commonly being seen today. ${ }^{8}$ Much of this perceived difficulty could be due to the lack of space and financial means that are necessary to resolve such large issues.

\section{LIMITATIONS}

In retrospect, asking nurses what year their emergency department was built or remodeled might have assisted in the analysis of why specific emergency nurses were either satisfied or dissatisfied with the design and layout of their emergency department. Nurses also could have been specifically asked how many shifts they worked and how many dying patients they cared for in a month. Increased specificity would have given clarity to the analysis of items. For example, if a nurse reported that design obstructed care of a dying patient once a month and that same nurse only cared for 2 dying patients in that same period, then the significance of that design obstruction would have greatly increased.

\section{IMPLICATIONS FOR EMERGENCY NURSES}

Obstacles such as ED design problems can negatively affect the ability of a nurse to provide excellent care and might cause work-related stress to these nurses who work in an already high-stress area. Department design changes should always be reviewed and approved by the emergency nurses working in that department. Emergency nurses should be viewed as an essential resource for administrators, architects, and hospital design teams as they implement their ideas for layout and design changes of emergency departments. Further evaluation regarding nurses' perceived difficulty with design changes to their departments is needed.

This study supports earlier work showing emergency nurses are interested in providing input that leads to better
EOL care. Hospital administrators, ED managers, and hospital design teams need to actively seek input from nurses regarding ED designs before building or remodeling emergency departments. In this way, department design will assist nurses in providing the best care to dying patients and their families. Listening to and implementing emergency nurses' recommendations regarding emergency department design might help alleviate one aspect of the burden of caring for dying patients. Listening to emergency nurses' suggestions could contribute to a better design and layout of emergency departments.

\section{Conclusions}

Although emergency design did not affect EOL care as significantly as we presumed prior to conducting this study, it did negatively affect emergency nurses' care of dying patients at a rate of more than once a month. EOL care to dying patients in emergency departments might be enhanced if improvements to ED design could be realized. Further research is needed to clarify the impact of ED design on EOL care. Committees that oversee the remodeling and construction of emergency departments should seek and incorporate the design suggestions of emergency nurses.

\section{REFERENCES}

1. Pitts SR, Niska RW, Xu J, Burt CW. National Hospital Ambulatory Medical Care Survey: 2006 Emergency Department Summary (US). Hyattsville, MD: National Center for Health Statistics; 2008. Report 7.

2. Heaston S, Beckstrand RL, Bond AE, Palmer SP. Emergency nurses' perceptions of obstacles and supportive behaviors in end-of-life care. J Emerg Nurs. 2006;32(6):477-85.

3. Beckstrand RL, Smith MD, Heaston S, Bond AE. Emergency nurses perceptions of size, frequency, and magnitude of obstacles and supportive behaviors in end-of-life care. J Emerg Nurs. 2008;34(4):290-300.

4. U.S. Department of Health \& Human Services. Summary of HIPAA privacy rule. http://www.hhs.gov/ocr/privacy/hipaa/understanding/summary/ index.html. Accessed June 14, 2009.

5. Infocus Marketing. Emergency Nurses Association. http://www.infocus lists.com/datacards/datacards/dc.aspx?id=79\&type=0. Updated June 15, 2011. Accessed February 6, 2012.

6. Judkins S. Pediatric emergency department design: Does it affect staff, patient, and community satisfaction? Emerg Med. 2003;15:63-7.

7. Emergency Nurses Association. End-of -life care in the emergency department. http://www.ena.org/SiteCollectionDocuments/Position\% 20Statements/EndofLifeCareintheEmergencyDepartment.pdf. Updated December 2010. Accessed February 6, 2012.

8. Zilm F. A new era of emergency care: planning and design consideration. J Amb Care Med. 2007;13(3):259-63. 